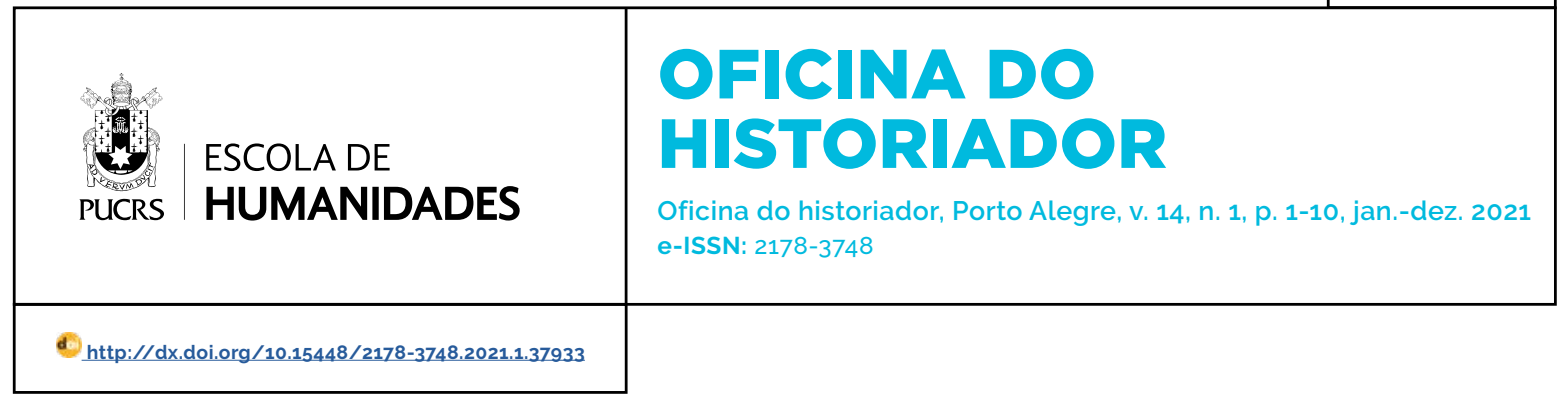

SEÇÃO: ARTIGOS

\title{
A Justiça do Trabalho e as disputas dos trabalhadores(as) pelo salário moléstia (1941-1945)
}

\author{
Labour Court and worker dispute about sick pay (1941-1945)
}

\author{
Tatiane Bartmann ${ }^{1}$ \\ orcid.org/0000-0002-0763-5485 \\ tati_bartmann@hotmail.com
}

Recebido em: 30/4/2020.

Aprovado em: 27/8/2020

Publicado em: 12/05/2021.
Resumo: A partir da análise dos processos trabalhistas iniciados pelos trabalhadores(as) contra um grupo de indústrias de Porto Alegre, fundadoras do Cinfa (Centro da indústria fabril) cujas reclamações se referiam principalmente ao auxilio-doença, objetiva-se verificar a atuação da Justiça do Trabalho, bem como alguns dos seus principios fundadores, as experiências dos trabalhadores nas disputas dos tribunais, a legislação existente que regulamentava o pagamento de salários ou auxilios em casos de enfermidade e as decisões da $1^{\text {a Junta de }}$ Conciliação e Julgamento desde a sua instalação (1941) até o final do Estado Novo (1945). Trata-se, portanto, do periodo inicial da organização e funcionamento da Justiça do Trabalho, uma espécie de tribunal administrativo do trabalho que possuia relativa autonomia devido sua vinculação ao Poder Executivo.

Palavras-chave: Justiça do Trabalho. Processos. Auxilio-doença.

Abstract: Based on the analysis of the labour cases initiated by the workers against a group of industries in Porto Alegre, founders of Cinfa (Centro da indústria fabril) whose complaints mainly referred to sickness benefits, the objective is to verify the performance of the Labour Court, as well as its founding principles, the experiences of workers in court disputes, the existing legislation that regulated the payment of salaries or aid in cases of illness and the decisions of the

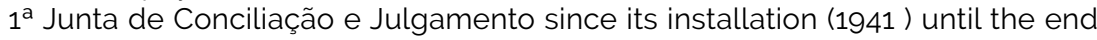
of the Estado Novo (1945). It is, therefore, the initial period of the organization and functioning of the Labor Court, a kind of administrative labor court that had relative autonomy due to its connection with the Executive Power.

Keywords: Labour Court. Labour Cases. Sick pay.

\section{Introdução}

A presente pesquisa tem o objetivo de analisar os processos movidos pelos trabalhadores(as) contra o grupo de empresas fundadoras ${ }^{2}$ do Cinfa

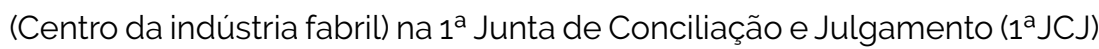
de Porto Alegre, desde a fundação da Justiça do Trabalho (1941) até o final do Estado Novo (1945). O foco principal de análise são as ações cujas reclamações se relacionam com situações de doença do empregado a fim de compreender como essas situações eram vivenciadas por eles, quais as leis existentes de amparo ao trabalhador, quais os argumentos utilizados pelos reclamantes (aqueles trabalhadores(as) que iniciavam

as ações trabalhistas) e reclamados (indústrias) para defender seus
Artigo está licenciado sob forma de uma licença Creative Commons Atribuição 4.0 Internacional.

\footnotetext{
Universidade Federal do Rio Grande do Sul (UFRGS), Porto Alegre, RS, Brasil.

1. As empresas reclamadas são: A. J. Renner e Cia; 2. Kluwe Müller e Cia; 3. Barcellos Bertaso e Cia; 4. Nedel Jung Hermann e Cia; 5. Húgo Gerdau; 6. Ernesto Neugebauer; 7. Walter Gerdau; 8. Otto Brutschke; 9. Wallig; 10. Cia de Vidros Sul-Brasileira; 11. Cia Fiação e Tecidos Porto Alegrense; 12. Tannhauser e Cia Ltda; 13. Cia Souza Cruz (fábrica); 14. Bopp. Sassen e Ritter e Cia; 15. Cia Geral de Indústrias: 16. Alberto Bins (Fábrica Berta).
} 
interesses e de que forma atuava a Justiça do Trabalho (JT) nesses processos.

Foram analisados 140 processos, ao todo. As reclamações que trazem menções a problemas de saúde e doenças, que incapacitavam os trabalhadores de continuar normalmente os seus serviços, são 19, ou seja, $13,5 \%$ do todo documental analisado. Entre esses, é possivel fazer algumas subdivisões para melhor compreensão das situações que levaram esses empregados(as) aos tribunais. Observou-se que desses 19 processos, 11 reclamavam o "salário moléstia" nos termos utilizados pelos próprios trabalhadores(as), atualmente denominado de "auxilio-doença". Esses processos são os que mais interessam para a presente pesquisa, pois trazem vários elementos para pensar respostas aos questionamentos acima levantados.

Nas outras 8 ações, os trabalhadores(as) reclamavam as rescisões contratuais fruto de faltas ao trabalho por enfermidades. Nessas ações, eles(as) declaravam que faltaram ao serviço por motivo de doença e ao retornarem recebiam a noticia de que a empresa já não tinha mais trabalho para eles(as), que já havia outro empregado em seu lugar ou que, diante do abandono de serviço, estava rescindido o contrato por justa causa. Nessas situações os reclamantes pediam, em geral, aviso prévio, indenização, férias não pagas ou a reintegração. Nestes casos, a maioria dos processos resultaram em acordo entre as partes, foram 6 processos que terminaram com a conciliação, uma procedência da reclamação ou condenação da empresa reclamada e uma improcedência da reclamação, onde o reclamante perdeu a ação.

O maior número de processos cuja reclamação mencionava doenças adquiridas sem relação com o trabalho, pedia o "salário moléstia", isto é, o pagamento do salário no primeiro mês de enfermidade. Esses processos são maiores e muitos foram considerados improcedentes, por isso se prolongavam mais se compararmos com aqueles terminados em conciliação. Essas ações apresentavam mais de uma audiência, onde a atuação da JT era, por vezes, questionada através de pedidos de exceção de incompetência por parte das indústrias reclamadas. Considerando que esses processos foram os primeiros tramitados na recém-criada JT, é intenção dessa pesquisa compreender quais os argumentos utilizados por essa nova instituição para reafirmar sua atuação, bem como, analisar na prática de mediação dos conflitos, os seus principios fundadores.

Além disso, os processos trabalhistas permitem também analisar as experiências ${ }^{3}$ dos(as) trabalhadores(as) que reivindicavam direitos na primeira instância da JT, especialmente, diante de problemas de saúde que os incapacitava de trabalhar normalmente. Seus depoimentos demonstram as concepções de justiça e direitos que possuiam, os embates nos tribunais ajudam a entender suas lutas e apropriações da legislação e dos espaços de poder, como veremos na sequência.

\section{Atuação e competência da Justiça do Trabalho}

Os dissidios oriundos das relações entre empregados e empregadores regulados na legislação social serão dirimidos pela Justiça do Trabalho; [...] considerando que a lei, em que se baseia o reclamante - Art. 121 do Decreto $n^{\circ}$ 5493, de 9-4-1940 - sem dúvida faz parte da legislação social; considerando, pois, que compete a esta Junta conhecer do presente feito. ${ }^{4}$

A $1^{a}$ Junta de Conciliação e Julgamento de Porto Alegre reafirmava assim, sua competência em conciliar e julgar conflitos trabalhistas normatizados pela legislação social. Este órgão de primeira instância da Justiça do Trabalho, instalado em 1941, durante o Estado Novo (1937-1941), resultou de debates envolvendo concepções políticas divergentes. Sendo, os que defendiam uma política intervencionista e autoritária do Estado, os condutores da organização estrutural da autarquia. Consequentemente, sua trajetória foi marcada por dissensos relativos à competência e reiteradas demonstrações de reafirmação da sua atuação

\footnotetext{
3 Trata-se aqui das experiências de luta dos(as) trabalhadores(as) nos tribunais do trabalho pela ampliação das leis trabalhistas e dos seus direitos. Nesse sentido, compreende-se a lei menos como "um instrumento de poder de classe do que uma arena central de conflito. Ao longo do conflito, a própria lei se alterou" (THOMPSON, 1987, p. 355).

4 Processo No $981 / 1944$ da $1^{\circ}$ JCJ de Porto Alegre.
} 
como mediadora nos dissídios provenientes das relações entre empregado e empregador.

O decreto $n^{\circ}$ 5493/1940, citado anteriormente, aprovava o novo Regulamento do Instituto de Aposentadoria e Pensões dos Comerciários. A partir desse, era normatizado o seguro-doença previsto ao contribuinte que se encontrasse debilitado temporariamente para o trabalho. Nestes casos, o empregado receberia o auxílio pecuniário relativo aos primeiros trinta dias em que estivesse doente. ${ }^{5}$ Embora esse decreto regulamentasse 0 seguro-doença estritamente aos trabalhadores do comércio, esse direito também era reclamado pelos operários das indústrias que reivindicavam o que eles denominavam de "salário moléstia".

Os empregados dos estabelecimentos industriais conquistaram direitos legais sobre o auxílio-doença em 26 de setembro de 1944. A partir do decreto n6905/44 ficava determinado que nos quinze primeiros dias de afastamento, por causa de enfermidade, o trabalhador de qualquer categoria profissional receberia o pagamento de dois terços dos salários que ele teria direito se estivesse desempenhando seus serviços. ${ }^{6}$ Assim, nas ações posteriores a data da instituição desse decreto, as reclamações passaram a se fundamentar na exigência ao cumprimento da lei prevista aos empregados, independentemente da categoria que ocupavam.

Mas, analisando os processos sob a vigência da Consolidação das Leis Trabalhistas (CLT/1943), anteriores a setembro de 1944, nota-se nas reclamações dos trabalhadores da indústria a menção ao benefício garantido aos empregados do comércio. Assim, considerando não haver legislação regulamentando o pagamento de seguro-doença ao trabalhador da indústria, os empresários levantaram pedidos de "exceção de incompetência da Justiça do Trabalho" argumentando que se tratavam de casos em que era invocada uma lei de previdência sem valor ao empregado de estabelecimentos industriais.

A exceção aludida baseava-se na CLT, artigo 12 - "Os preceitos concernentes ao regime de seguro social são objeto de lei especial", combinado com o artigo 643 - "Os dissídios, oriundos das relações entre empregadores e empregados reguladas na legislação social, serão dirimidos pela Justiça do Trabalho".7 Nesse sentido, os empregadores argumentavam que a lei referente ao auxilio-doença pelo seu caráter especial, não fazia parte da legislação social. Com isso, afirmavam que a reclamação não possuía apoio legal, "não podendo além disso, ser invocada a analogia e equidade, por não caber no caso", por isso, levantavam a exceção de incompetência da JT. ${ }^{8}$

No entanto, a Justiça do Trabalho rebatia o pedido de exceção de incompetência e, com isso, reafirmava sua atuação argumentando que apesar do reclamante exigir um direito garantido apenas ao empregado do comércio, esse código legal sem dúvida estava incluso na legislação social. A partir do artigo 643 da Consolidação, trecho citado pelos próprios empresários, a JT afirmava-se apta a atuar dirimindo os conflitos regulamentados na legislação social. Sendo assim, "resolve a $1^{\text {a }} \mathrm{JCJ}$ em face do exposto e por unanimidade de votos, julgar improcedente a exceção levantada e considera-se competente para apreciar o presente dissídio". ${ }^{9}$

É importante chamar a atenção para a utilização do artigo 643 da CLT tanto por parte dos empresários abrindo o pedido de incompetência, quanto por parte da própria JT para reafirmar sua competência e atuação no processo em questão. Ambos voltavam o foco para o conceito de "legislação social". Enquanto os empregadores afirmavam que uma lei especial não fazia parte da legislação social, a primeira instância da JT compreendia o conceito de legislação social de maneira bastante ampla e

\footnotetext{
5 BRASIL, Decreto n 5493/1940 Artigo 121 "incumbirá ao empregador o pagamento dos vencimentos do empregado correspondentes aos primeiros trinta dias de seu afastamento do serviço". Disponivel em: http://ww/w2.camara.leg.br/legin/fed/decret/1940-1949/decreto-5493-9-abril-1940-344385-publicacaooriginal-1-pe.html. Acesso em: 10 mar. 2020.

6 BRASIL. Decreto-lei No 6905/1944. Disponivel em: http://presrepublica.jusbrasil.com.br/legislacao/126613/decreto-lei-6905-44\#art-2. Acesso em: 12 mar. 2020.

BRASIL. Decreto $n^{\circ} 5.452$, de $1^{\circ}$ de maio de 1943. Aprova a Consolidação das Leis do Trabalho. Artigo 643. Disponivel em: http://www. planalto.gov.br/ccivil_03/decreto-lei/del5452.htm. Acesso em: 12 mar. 2020

8 Processo $\mathrm{N}^{\circ}$ 981/1944 da $1^{\circ} \mathrm{JCJ}$ de Porto Alegre.

9 Processo $\mathrm{N}^{\circ}$ 981/1944 da $1^{\circ} \mathrm{JCJ}$ de Porto Alegre.
} 
geral. Pensando na JT recentemente implementada e na área do direito do trabalho que estava em formação, é esperado que muitas discussões sejam feitas para pensar inclusive na maneira de interpretar as leis sociais ou a legislação trabalhista.

Conforme o curso de Legislação Brasileira do Trabalho ministrado por W. Niemeyer, assistente técnico do Ministro do Trabalho, Indústria e Comércio e diretor de seção do Conselho Nacional do Trabalho, em 1936, a legislação do trabalho "é um ramo jurídico de recente formação" que possui "pontos de contato com a economia política, com a história, com o direito constitucional, administrativo, civil e penal", muito embora, seu desenvolvimento cresceu de maneira que "os mestres com a illustração do acatado professor Waldemar Ferreira depois de referir a larga variedade de relações juridicas que offerece, aceitam-no como um direito autonomo". Tratando sobre as possiveis definições conceituais sobre o novo ramo do direito o qual apresenta suas singularidades próprias, Niemeyer explica, então, que a legislação social ou, mais especificamente, o "Direito Social" seria uma denominação demasiadamente ampla para a legislação trabalhista, "pois todo direito que é feito para a sociedade é direito social" (NIEMEYER, 1936, p. 16).

Pelo que se pode observar, essas interpretações amplas e gerais contribuiam para a JT se consolidar como mediadora dos conflitos entre empregados e empregadores, independentemente do assunto em discussão, seja ele regulamentado pela legislação trabalhista ou por uma lei especial, todos esses dispositivos se relacionavam à legislação social e, como consta na CLT, seria competência da JT atuar nesses casos. Assim, toda essa interpretação mais flexivel das leis estava em discussão, na década de 1930 , e se relacionava com a proposta de criação e fundamentação da justiça.

O modelo de Justiça do Trabalho criado pelo Estado Novo resultava de um longo e denso debate acerca dos seus principios jurídico-po- líticos fundamentais. Ele se deu principalmente entre Oliveira Viana, ${ }^{10}$ membro da comissão de técnicos do Ministério do Trabalho, e o deputado Waldemar Ferreira ${ }^{11}$, critico às ideias de Vianna. $\mathrm{O}$ seu conteúdo envolvia, entre outras questões, o principio que rege o Direito de forma ampla e geral. A esse respeito, Oliveira Viana (1938) explicava a existência de duas correntes interpretativas das leis em geral. A primeira baseava-se no método interpretativo onde "o sentido do dispositivo constitucional é o que resulta da sua letra". Por outro lado, conforme observava o autor, a partir da análise do exemplo dos Estados Unidos, a segunda corrente utiliza-se do método "construtivo" que não está mais focado na letra da lei, pelo contrário, "vai além, transcende o domínio do puro direito formal" (VIANA, 1983, p. 26).

Segundo Viana, essas duas formas distintas de compreensão do texto constitucional, formam dois grupos, "duas verdadeiras escolas", em que se destaca o "método clássico"12 e o "método sociológico ou realista"13. Na elaboração da sua argumentação, o autor promove um debate rico entre diversos e distintos autores e explica as caracteristicas que distinguem essas duas "Escolas". Seu objetivo é fundamentar a criação da JT dentro do novo padrão interpretativo das leis, conforme o "método sociológico ou realista" que promove a interpretação legal de maneira mais flexivel.

A organização da JT foi, portanto, pautada na proposta de cunho autoritário que visava à flexibilização nas interpretações até mesmo do Direito Constitucional a fim de dar a esse órgão trabalhista certa autonomia através do poder normativo que, segundo Viana, seria necessário para a mediação dos conflitos resultantes da sociedade industrializada. Rebatendo assim, a maior crítica de Waldemar Ferreira que considerava o poder normativo da JT, um ato inconstitucional. Essa nova forma interpretativa das leis, além de flexibilizar as interpretações constitucionais a fim de dar a JT certa autonomia, também modificava a atuação dos juízes e, por sua vez, interferia nos tramites processuais.

\footnotetext{
Oliveira Viana destaca-se na elaboração do projeto de organização da Justiça do Trabalho. Ver: VIANA, 1983. Ver: FERREIRA, [1938?].

"Old school, de Corwin, da mechanical jurisprudence, de Pound" (VIANA, 1983, p. 27).

"New school, da sociological jurisprudence de Llewellyn (Holmes, Brandeis, Stone, Cardozo)" (VIANA, 1983, p. 27).
} 
A partir de 1930, a tendência política discursiva enfatizava a legislação trabalhista como sua mais significativa criação. Nesse sentido, no curso de legislação trabalhista, citado anteriormente, apresentado por W. Niemeyer em 1936, o jurista afirmava que "o Brasil, chegou até 1930 com uma legislação falha e muito deficiente" conforme o assistente técnico do Ministro do Trabalho e diretor de seção do Departamento Nacional do Trabalho, "só tinhamos, em matéria de legislação as leis sobre accidentes de trabalho, pensões e aposentadorias para ferroviários e férias para os empregados do comércio" dentre outras leis avulsas sobre a organização dos sindicatos (NIEMEYER, 1936, p. 61).

Niemeyer se referia à Lei 3.724 de 1919 que previa indenização por acidentes de trabalho. Em 1923, a Lei 4.682 criava as Caixas de Pensões e Aposentadoria para os ferroviários e, no ano de 1925, a Lei 4.982 determinava quinze dias de férias anuais e remuneradas aos trabalhadores do comércio, indústria e bancários. ${ }^{14}$ Ainda que este conjunto possa ser caracterizado como "falho e deficiente", trata-se uma legislação incipiente que marcou o início da regulamentação de temáticas que foram posteriormente reformuladas e mais precisamente normatizadas.

Sendo assim, os trabalhadores que iniciaram processos reivindicando o cumprimento dos direitos relativos ao auxilio-doença, em especial, não abordavam assuntos completamente novos do âmbito da legislação social. Essas temáticas se fizeram presente no conjunto das leis sociais já na Primeira República ${ }^{15}$ e foram se expandindo através das pressões dos trabalhadores que reivindicavam direitos, entre outras formas, na JT, como veremos adiante.

\section{A luta pelo direito de adoecer}

[...] a firma reclamada tem fornecido assistência médica e medicamentos, porque assim o devia; que de qualquer forma o reclamante teria direito a mesma, visto que contribui para uma caixa de auxilio mútuo; que, assim, se julga com direito ao pedido inicial. ${ }^{16}$

Em audiência na $1^{\text {a }}$ Junta de Conciliação de Julgamento, Eugênio Gondran Pinto, trabalhador há mais de quatro anos na empresa Cia de Cigarros Souza Cruz, exercendo a função de mecânico eletricista, reivindicava o direito ao salário moléstia e afirmava não ter recebido caridade da firma reclamada, nem na assistência médica, nem nos medicamentos fornecidos, pois se tratava de um direito. As caixas de auxilio mútuo, referidas na citação, foram criadas nas primeiras décadas do século XX por iniciativa dos trabalhadores, nas quais empregados e empregadores colaboravam a fim de garantir os recursos básicos aos operários em casos de doença ou velhice. ${ }^{17}$

No entanto, em 1936, através da Lei nº 367 era criado o Instituto de Aposentadoria e Pensões dos Industriários (IAPI), contando com uma "contribuição tríplice e igual dos empregados, empregadores e da União". ${ }^{18}$ Existiam diferenças significativas entre os IAPs e as caixas de auxílio mútuo, sendo que essas últimas eram organizadas e administradas pela empresa, enquanto os IAPs foram instituidos por categorias profissionais e estavam subordinados ao Ministério do Trabalho, Indústria e Comércio, portanto, vinculado ao Estado.

Possivelmente, a contribuição à caixa de auxilio mútuo que o trabalhador declarou em audiência, era referência ao desconto do IAPI, no entanto, conforme essa lei, os trabalhadores contribuintes somente teriam direito a esse auxilio pecuniário em decorrência de moléstia a partir do $30^{\circ}$ dia do seu afastamento. Portanto, aqueles primeiros 30

\footnotetext{
14 BRASIL. Decreto-lei n 3.724, de 1919. Regula as obrigações resultantes dos acidentes de trabalho. Disponivel em: https://www2. camara.leg.br/legin/fed/decret/1910-1919/decreto-3724-15-janeiro-1919-571001-publicacaooriginal-94096-pl.html. Acesso em: 5 fev. 2020; BRASIL. Decreto $n^{\circ} 4.682$ de 1923. Disponivel em: http://www.planalto.gov.br/ccivil_03/decreto/historicos/dpl/DPL4682-1923. htm. Acesso em: 05 fev. 2020; BRASIL. Decreto n 4.982/1925. Disponivel em: https://www2.camara.leg.br/legin/fed/decret/1920-1929/ decreto-4982-24-dezembro-1925-776548-publicacaooriginal-140498-pl.html. Acesso em: 10 fev. 2020.

15 Ver: GOMES, 1994.

16 Processo $N^{\circ} 3707 / 1944$ da $1^{\circ} \mathrm{JCJ}$ de Porto Alegre

17 Sobre esse assunto, ver: BATICH, 2004.

18 Lei No 367, de 1936. Criava o Instituto de Aposentadoria e Pensões dos Industriários. Disponivel em: https://www2.camara.leg.br/ legin/fed/lei/1930-1939/lei-367-31-dezembro-1936-555119-publicacaooriginal-74230-pl.html. Acesso em: 12 mar. 2020.
} 
dias pedidos em reclamação na JT, a legislação trabalhista não regulamentava. Apesar disso, Eugênio considerava injusto não receber salário no primeiro mês de enfermidade, e reivindicava seu direito ao auxílio.

Eugênio apresentou sua reclamação em agosto de 1943, na qual declarava que ficou doente e a empresa lhe pagou apenas parte daquilo que teria direito frente ao primeiro mês de enfermidade, cito sua reclamação:

que o reclamante tendo ficado doente e estando agora por conta do Instituto recebeu da firma reclamada a importância de CR $\$ 187,50$ restando ainda a importância de CR\$ 332,50, importância essa de um mês de salário que esteve doente e que a firma negou-se a the pagar alegando que não existe lei mandando o empregador pagar ao empregado o primeiro mês de salário quando este adoece. ${ }^{19}$

O decreto que normatizava o seguro-doença previsto ao contribuinte que se encontrasse debilitado temporariamente para o serviço e que garantia ao trabalhador o primeiro mês de salário era o Decreto n 5493/1940. Esse, aprovava o novo Regulamento do Instituto de Aposentadoria e Pensões dos Comerciários.

Assim, Eugênio e outros(as) 10 reclamantes, trabalhadores(as) da indústria, reivindicavam um direito legalmente garantido apenas a categoria dos comerciários. Apesar das reclamações iniciais dos empregados não citarem diretamente o Decreto $n^{\circ}$ 5493/1940, eles pediam exatamente o que a lei garantia aos trabalhadores do comércio, provavelmente em uma tentativa de expandir os direitos já conquistados para as demais categorias.

Assim como a reclamação de Eugênio, outros seis trabalhadores e quatro trabalhadoras reclamavam o auxilio-doença. Além da empresa de cigarros Souza Cruz, os processos eram movidos contra os seguintes reclamados, o número de processos consta entre parênteses: (2) Alberto Bins (Fábrica Berta), (1) Cia de Vidros Sul Brasileira, (2) Cia Fiação Tecidos Porto Alegrense, (3) A. J. Renner e Cia, (1) Ernesto Neugebauer e Cia, (1) Cia Geral de Indústrias. Dessa forma, das 16 empresas reclamadas (fundadoras do Cinfa), sete receberam reclamações quanto ao não pagamento do salário moléstia. A partir disso, é possivel afirmar que essa demanda dos trabalhadores(as) por auxilio-doença, significando melhores condições de vida e de trabalho, era formalmente conhecida por considerável parte das indústrias reclamadas, mais precisamente, por $43,7 \%$ delas.

Continuando no processo de Eugênio, a empresa reclamada declarou que de fato não reconhecia o direito do empregado da indústria ao "salário moléstia", pois não existia lei especifica garantindo esse benefício à categoria de trabalhadores em que se inseria o reclamante. E ainda afirmou que "mesmo sem ter qualquer obrigação, a firma reclamada, [auxiliou] o reclamante, com parte de seus salários, além de assistência médica e medicamentos"20.

Assim, a empresa reclamada reafirmava sua postura como provedora do bem-estar do trabalhador. Porque, mesmo não sendo legalmente obrigada a auxiliar o empregado adoentado, forneceu a Eugênio, além da ajuda imediata na forma de medicamentos e assistência médica da qual necessitava, parte do seu salário. Esse argumento reforçava a imagem benevolente dos empresários e associava os direitos dos trabalhadores aos atos de caridade dos empresários.

Segundo Margareth Rago (1987) essa prática faz parte da pedagogia paternalista dos patrões, que possuiam a intenção de reforçar sua autoridade e "assegurar a integração do trabalhador ao aparato produtivo" (RAGO, 1987, p. 33-34). Essa estratégia pode ser compreendida como uma forma refinada de disciplinar o trabalhador que destituido de direitos, receberia caridade e, por isso, deveria sentir-se grato.

No entanto, esse mesmo trabalhador não aceitava facilmente essa imposição, os vários processos trabalhistas iniciados por operários(as) que reclamavam o direito de receber o salário mesmo quando estavam incapacitados de trabalhar, demonstra que esse discurso paternalista não era recebido da maneira como o empregador gostaria. Os conflitos não eram abafados com a 
simples negação do patronato aos pagamentos solicitados pelos trabalhadores, a luta por direitos extrapolava as dependências fabris e ocorria também na recém implementada JT.

Apesar da $1^{\text {a }} \mathrm{JCJ}$ reconhecer sua competência em conciliar ou julgar esses conflitos referentes a uma lei especial, conforme foi abordado na primeira parte desse artigo, quanto ao pedido de exceção de incompetência, no momento de exercer o julgamento do processo, prevaleceu a consideração de que Eugênio era operário da indústria e não do comércio. Por causa disso, a $1^{\text {a }} \mathrm{JCJ}$ julgava improcedente a reclamação considerando que:

efetivamente não há dispositivo legal que ampare o empregado na indústria e que determine o pagamento de um mês de salário durante a enfermidade do empregado; considerando que esse direito constitui uma prerrogativa do empregado no comércio. ${ }^{21}$

Esse processo analisado de Eugênio assemelha-se a outros, como o de Euripides Rodrigues, auxiliar de encaixotador na Companhia de Vidros Sul Brasileira. Eurípides trabalhava na empresa há, aproximadamente, dois meses quando se afastou por dezesseis dias por problemas de saúde. Em sua reclamação, pede que seja pago o "salário-moléstia" pelos dias em que não pode trabalhar.

Como no processo anterior, a empresa afirma ser improcedente a reclamação, pois o empregado da indústria não teria direito ao auxílio-doença que era um benefício do comércio. A ação de Euripedes, da mesma forma que a de Eugênio, também resultou em improcedência. $\mathrm{Na}$ sentença, a $1^{\text {a } ~ J C J ~ a p o n t a ~ a s ~ d i f e r e n c ̧ a s ~ e n t r e ~ o s ~}$ trabalhadores do comércio e da indústria, cito:

sendo o reclamante um empregado na indústria, e, portanto contribuinte do Instituto dos Industriários, não se the podem aplicar dispositivos legais constantes de decreto $n^{\circ} 5493$, o que regulamentou o Instituto dos Comerciários; considerando assim, que nenhum dispositivo legal ampara a presente reclamação, e que não é possivel invocar no presente caso como em outros semelhantes a analogia ou a equidade, porque comerciários e industriários, são classes que, pela natureza mesmo do trabalho exe- cutado diferem diametralmente, considerando que tanto é assim, que a legislação trabalhista não hesitou em estabelecer salários mínimos diversos para as classes mencionadas. ${ }^{22}$

Diante disso, por maioria dos votos a $1^{\text {a }} \mathrm{JCJ}$ resolve julgar improcedente a reclamação. Assim como nessas duas análises das experiências dos trabalhadores Eugênio e Euripedes, outros reclamavam o auxilio pecuniário pelos dias em que o trabalhador não compareceu à firma por causa de enfermidade. Em todos os casos julgados até setembro de 1944, a primeira instância da JT dizia ser competente em atuar, mas não reconhecia o direito de os empregados da indústria receberem o pagamento do auxílio-doença.

Apesar dos resultados negativos, os trabalhadores continuavam demandando auxilio-doença. Até que, em 26 de setembro de 1944, pelo Decreto $n^{\circ} 6905 / 1944$, foi garantido ao trabalhador de qualquer categoria, nos quinze primeiros dias de afastamento por causa de enfermidade, o pagamento de dois terços dos salários que o empregado receberia nesse período ${ }^{23}$, a ser pago pelo empregador. Analisando os processos ajuizados depois da instituição desse decreto, percebe-se uma grande mudança nos resultados dessas ações como poderá ser observar no caso que será analisado na sequência.

Luiza Silva Cláudio era empregada com estabilidade da empresa Ernesto Neugebauer e Cia. Em outubro de 1944, ela iniciou o processo trabalhista reclamando o pagamento dos dias em que esteve afastada do serviço por motivos de doença. Assim, a ação de Luiza assemelha-se muito à reclamação, anteriormente tratada, do empregado Eugênio, como pode se observar na sua declaração inicial:

que esteve enferma, impossibilitada de trabalhar, de 22 de agosto a 22 de setembro, conforme prova com o incluso atestado médico; diante do exposto, requer que $\mathrm{V}$. S. mande citar a firma reclamada para ver-se-lhe propor a presente ação, sob pena de revelia, e afinal, ser condenada a pagar á reclamante a importancia de $\mathrm{Cr} \$ 370,00$ correspondente a 25 dias de salário. ${ }^{24}$

22 Processo Nº 981/1944 da $1^{\circ} \mathrm{JCJ}$ de Porto Alegre.

23 Decreto No 6905/1944. Disponivel em: http://www.planalto.gov.br/ccivil_03/Decreto-Lei/1937-1946/Del6905.htm. Acesso em: 12 mar. 2020.

24 Processo $N^{\circ} 1731 / 1944$ da $1^{\circ}$ JCJ de Porto Alegre. 
Esse processo, provavelmente, teria o mesmo desfecho dos demais analisados, se tramitasse antes da data do Decreto n ${ }^{\circ} 6905 / 44$. Ele seria considerado improcedente como os 5 processos que tramitaram antes de setembro de 1944 , todos com argumentos muito semelhantes da

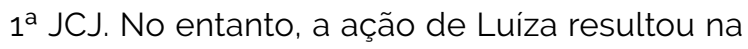
conciliação entre as partes e ficou acordado que a reclamante receberia no ato a quantia de $\mathrm{Cr} \$$ 148,00 (cento e quarenta e oito cruzeiros), valor correspondente ao salário moléstia.

Observa-se, porém, que o pedido inicial da reclamante Luiza era de $\mathrm{Cr} \$ 370,00$ (trezentos e setenta cruzeiros) referentes aos vinte e cinco dias de afastamento. Essa diferença entre o valor exigido na reclamação e a quantia realmente recebida com a conciliação poderia ser compreendida como prejuizo ao trabalhador e, assim, se sustentaria a ideia de uma "justiça com desconto" formulada por French (2001). A partir dessa perspectiva, a conciliação era vista com uma conotação negativa, porque com o acordo, o trabalhador obteria um valor muito inferior ao pedido no início da ação.

No entanto, o Decreto n 6905/1944 regulamentava o pagamento de apenas dois terços do salário, relativo aos quinze primeiros dias em que o empregado estivesse debilitado por razão de enfermidade. Considerando isso, é possivel supor que o valor reclamado poderia estar acima do garantido por lei. Nesse sentido, a conciliação não implicaria, necessariamente, em "desconto". Sobre esse assunto, Clarice Speranza (2013) afirma que, nos anos 1940, "os trabalhadores já haviam aprendido que um acordo poderia significar 'dinheiro na mão' em contraponto à tramitação incerta e lenta de um processo judicial" (SPERANZA, 2013, p. 54).

Como se pode observar ainda, a simples existência da lei não garantia o pagamento do auxilio-doença aos trabalhadores, uma vez que a operária Luiza precisou acionar a JT para fazer a cobrança. Da mesma forma, outros(as) cinco operários(as) também reclamaram o pagamento do "salário moléstia".

Interessante notar a mudança na elaboração da reclamação de alguns, que passaram a pedir o pagamento de dois terços dos seus salários, conforme o novo decreto de 1944. Isso pode ser interpretado como demonstração de conhecimento da legislação por parte do trabalhador. mas também pode ser influência dos funcionários responsáveis pela atermação.

Dos resultados dos seis processos encontrados reclamando salário moléstia, após setembro de 1944, todos terminaram em acordo entre as partes, foram quatro conciliações e duas desistências. Essas desistências também são interpretadas como acordos, uma vez que, os(as) reclamantes compareceram na Junta dizendo que já haviam feito um acordo com o patrão e, por isso, gostariam de desistir das ações na JT.

Assim, a implementação de novas leis trabaLhistas mudava os desfechos dos processos e os trabalhadores fazendo uso delas, negociavam seus interesses. Nesse sentido, Jorge Ferreira, analisando como os trabalhadores receberam e se apropriaram do projeto estatal da Era Vargas, afirma que a intervenção estatal, "não impedia os trabalhadores na época de Vargas de identificarem seus problemas de classe, apontarem as soluções que convinham a seus interesses e lutarem por elas" (FERREIRA, 1997, p. 55). Ele destaca ainda, que nesse canal de comunicação entre o Estado e a sociedade, que era a JT "em geral, a variável central para o atendimento ou não dos pedidos era a legislação em vigor" (FERREIRA, 1997, p. 79).

De fato, a análise empírica nos processos trabalhistas reforça essas ideias formuladas por Ferreira (1997). São muitas reclamações de trabalhadores e trabalhadoras na $1^{\text {a }} \mathrm{JCJ}$ de Porto Alegre desde sua instalação até 1945, ano limite do levantamento e análise da pesquisa apresentada. Mas, através de uma observação rápida do acervo, preservado no Memorial do TRT4, percebe-se o aumento nos números de processos iniciados tanto na $1^{\text {a }} \mathrm{JCJ}$ quanto na $2^{\mathrm{a}} \mathrm{JCJ}$ nos anos subsequentes ao final do Estado Novo.

Sendo assim, os tribunais tornavam-se lugares de luta pela expansão de direitos e pela sua aplicação. Se a simples existência das leis trabalhistas não garantisse sua efetiva aplicação, a legislação dava ao trabalhador maiores possibilidades de 
êxito nas disputas dos tribunais, garantindo a ele maiores chances de conseguir resultados favoráveis como é o caso das conciliações.

\section{Considerações finais}

A Justiça do Trabalho, um órgão do poder estatal fruto do Estado Novo, foi criada para dirimir os conflitos entre empregados e empregadores, ora conciliando, ora julgando as reclamações. Sua estrutura e organização foi motivo de muito debate político-jurídico, representado pelas ideias de Oliveira Viana e Waldemar Ferreira os quais defendiam ideias divergentes. Essas discordâncias giravam principalmente em torno do poder normativo e até os dias atuais essas questões são fontes de muitas indagações.

Viana defendia uma interpretação mais realista da legislação constitucional brasileira, deixando de estar centrada na letra da lei, assim, mais flexivel e voltada para as demandas nacionais. Segundo ele, as novas relações sociais e econômicas marcavam variações bastante rápidas das condições do trabalho e precisavam da agilidade de um órgão técnico e eficiente, pois a morosidade da justiça comum não seria capaz de responder rapidamente aos problemas colocados pelos conflitos entre patrões e empregados (VIANA, 1983, p. 41-50).

O que era uma tentativa de diminuir os conflitos entre patrão e empregado, acabou se mostrando um espaço de disputas. Dentro dessa nova proposta intervencionista da JT, os trabalhadores compreenderam uma oportunidade de reivindicar direitos, reclamar um trabalho mais justo, seguro e em melhores condições. Essa ideia de conjunto de direitos formulados em beneficio dos trabalhadores era veiculada pelo discurso político nas décadas de 30 e 40. ${ }^{25}$ Conforme French (2001), os trabalhadores compreendiam a legislação trabalhista como "um conjunto de direitos e obrigações legais". Por sua vez, apropriando-se dos dispositivos legais, buscavam por melhores condições de trabalho.

Ao analisar as frequentes reclamações, em especial, as que versavam sobre o auxilio-doença, identifica-se entre os trabalhadores das indústrias pedidos de direitos garantidos por lei, apenas a uma determinada categoria, a dos comerciários. Essas recorrentes demandas podem ser interpretadas como uma tentativa de ampliação de direitos através da atuação da JT.

Comparando os julgamentos das ações trabalhistas tramitadas antes e depois da implementação da Lei n 6905/44 que garantia o direito ao auxilio-doença a todas as categorias profissionais, observa-se uma grande mudança. Uma vez que os processos anteriores terminaram, em sua maioria, com a improcedência da reclamação, as ações posteriores a vigência dessa lei tiveram resultados mais positivos para os operários, terminando em conciliação. Dessa forma, é possivel afirmar que a simples existência da legislação, nem sempre significava garantia de direitos aplicados, mas certamente possibilitavam maiores chances de conquistas positivas na JT.

\section{Referências}

BATICH, Mariana. Previdência do trabalhador: uma trajetória inesperada. Perspectiva, São Paulo, v. 18, n. 3, jul./set. 2004. Disponivel em: https:// www.scielo.br/scielo.php? script=sci_arttext\&pi$\mathrm{d}=$ S0102-88392004000300004 Acesso em: 15 abr. 2020.

FERREIRA, Jorge (org.). Trabalhadores do Brasil: o imaginário popular. Rio de Janeiro: Editora FGV, 1997.

FERREIRA, Waldemar. Principios de Legislação Social e Direito Judiciário do Trabalho. Brasilia: Câmara dos Deputados, [1938?]. v. 2

FONSECA, Pedro Cezar Dutra. Vargas: o capitalismo em construção 1906-1954. São Paulo: Brasiliense, 1989.

FRENCH, John D. Afogados em Leis: a CLT e a cultura política dos trabalhadores brasileiros. São Paulo: Editora Fundação Perseu Abramo, 2001.

GOMES, Ângela Maria de Castro. A invenção do trabalhismo. 2. ed. Rio de Janeiro: Relume Dumará, 1994.

NIEMEYER, W. Curso de legislação brasileira do trabalho. Rio de Janeiro: A. Coelho Branco, 1936.

RAGO, Margareth. Do Cabaré ao Lar: a utopia da cidade disciplinar. Brasil 1890-1930. Rio de Janeiro: Paz e Terra, 1987. 
SPERANZA, Clarice Gontarski. Nos Termos das Conciliações: Os acordos entre Mineiros de Carvão do Rio Grande do Sul e seus Patrões na Justiça do Trabalho entre 1946 e 1954. In: GOMES, Ângela de Castro; SILVA, Fernando Teixeira da. A Justiça do Trabalho e sua História. Campinas: Editora Unicamp, 2013.

THOMPSON, Edward Palmer. Senhores e Caçadores Rio de Janeiro: Paz e Terra, 1987.

VIANA, Oliveira. Problemas de Direito Corporativo. 2 ed. Brasilia: Câmara dos Deputados, 1983.

\section{Tatiane Bartmann}

Doutoranda do Programa de Pós-Graduação em História da Universidade Federal do Rio Grande do Sul (UFRGS), em Porto Alegre, RS, Brasil; bolsista CAPES.

\section{Endereço para correspondência}

Tatiane Bartmann

Universidade Federal do Rio Grande do Sul

Av. Bento Gonçalves, 9500, prédio 43322, sala 205

Agronomia, 91509900

Porto Alegre, RS, Brasil 